\title{
Parallels Between COVID-19 and Antimicrobial Resistance: To What Extent Are We Willing to Accept Negative Personal Consequences for the Health of Others?
}

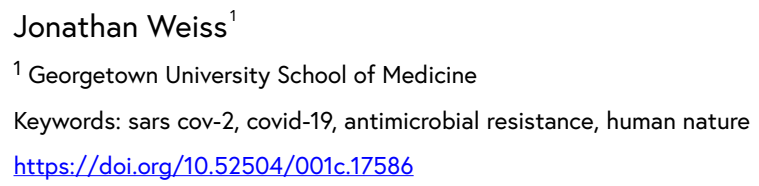

Georgetown Medical Review

Vol. 5, Issue 1, 2021

\begin{abstract}
Antimicrobial resistance (AMR) has been a significant concern for public health and is likely to get worse without collaborative efforts worldwide. Management of the current coronavirus disease 2019 (COVID-19) may further accelerate resistance patterns with the increased nonspecific antibiotic use for patients infected with the novel coronavirus, in an attempt to avoid secondary bacterial and fungal infections. ${ }^{1,2}$ Simultaneously, worldwide responses to the current pandemic have highlighted elements of human nature and societal collaboration that invite cautious optimism about humanity's ability to prepare for and manage confrontations with incoming pathogens.
\end{abstract}

\section{Introduction:}

Antimicrobial resistance (AMR) is a worldwide crisis. ${ }^{3}$ In 2014, the Review on Antimicrobial Resistance found that more than 700000 people die each year around the world due to AMR. ${ }^{4}$ For comparison, as of June 12, 2020, the World Health Organization estimated that around 418000 people have died of coronavirus disease 2019 (COVID-19). ${ }^{5}$ The issue of AMR will likely worsen, with the Review on Antimicrobial Resistance estimating that, without intervention, the world could witness 10 million deaths due to AMR annually by the year 2050. ${ }^{4}$ While some might dismiss such an estimate as hyperbole, organizations such as the World Health Organization cite this number in their literature, ${ }^{6}$ and many infectious disease specialists are voicing concern with similar intensity. ${ }^{7,8}$ Several infectious disease physicians now dedicate significant portions of their time to concerns of this nature as antibiotic stewards. Programs for antibiotic stewardship, the practice of carefully considering antibiotic use to treat infections while minimizing overuse, ${ }^{9}$ are now incorporated into many hospital systems and long-term care facilities.

A central tension exists in antimicrobial stewardship: the maximally protective choice for an individual patient often does not align with the most prudent choice for society, which is the combination of present and future patients. Antimicrobial agents are often appropriate to use. Still, prescribers are now encouraged, and sometimes required, to consider the notion that every antimicrobial prescription for current patients transfers some amount of risk to future patients. Infectious disease specialists who are working as stewards, other physicians who are confronted with limitations of prescribing options due to stewardship programs, and bioethicists in the field are acutely aware of 
the challenges that come with balancing inherently conflicting realities. The central question I will pose summarizes these challenges: Under what circumstances, if any, can an individual patient's risk of morbidity and/or mortality be knowingly increased to protect future patients?

With such a complex question, maybe the most appropriate next step is to outsource. What do patients and potential future patients think about the above question? While a controlled study or survey designed around this question would be ideal, the current COVID-19 crisis offers a valuable example to evaluate attitudes. To do this, I will rephrase and broaden the above question: To what extent are people willing to accept negative personal consequences, such as social and economic hardship, to protect the health of others?

\section{Limitations:}

I can envision a number of limitations to the approach of this paper. First, without performing a study, these assessments are anecdotal and, as such, are prone to my own observer and availability bias. Second, the comparison between patients who are prescribed fewer antimicrobials in order to slow resistance (group A) and individuals in the community who are isolating themselves, foregoing economic opportunities, and delaying medical care unrelated to COVID-19 in order to slow the spread of the virus (group B) is not perfect. The consequences of under prescription of antimicrobials are directly tied to health, while the consequences of physical isolation and quarantining practices are more closely associated with social and economic well-being. Nonetheless, choices to isolate due to COVID-19 confer adverse health outcomes as people postpone preventive care and may be less inclined to seek treatment for acute needs. Third, the world is currently in the midst of the pandemic, which makes stepping back and observing the big picture difficult.

Fourth, sparked by the death of George Floyd while in police custody, many have added the variable of race relations to their risk-benefit calculations. From one perspective, the gathering of thousands of people in protest, supported by many public health officials, ${ }^{10,11}$ seems to counteract previous precautions and recommendations. From another perspective, the protests are a reflection of many people's perception of the broad picture of public health. There are a complex set of factors at play, but for our purposes, I will not comment on the political elements of the movement and will instead focus on the motivations of those involved in the protests. We see many joining the demonstrations not necessarily for themselves, but rather to raise their voices for other people who they perceive to be in danger. In this sense, while the protests may increase the case burden of COVID-19, some part of the protests are a reflection of the capacity to care about the well-being of others.

Despite these limitations, parallels exist between COVID-19 and AMR and these parallels may help illuminate best practice approaches to impede infectious pathogens that await our missteps. 


\section{Reasons People Have Been Isolating During COVID-19:}

A sweep of news outlets and social media will demonstrate that, in general, people in the United States have followed guidelines to limit the spread of severe acute respiratory syndrome coronavirus 2 (SARS-CoV-2), most clearly shown through physical distancing and wearing masks during limited excursions to shared spaces. Furthermore, it appears that many of the participants in recent protests have been wearing masks and attempting to maintain distance from each other. ${ }^{12}$ There are multiple reasons that people follow these guidelines; these include (1) fear for personal health, (2) fear of transmitting the virus to vulnerable family members or close friends, and (3) fear of being a vector for the virus in the community at large.

People weigh each of the aforementioned reasons differently depending on personal circumstances and attitudes. Some who fit the profile of "high risk" might be more inclined to act out of concern for their own health. Although some may fear for their safety, young and healthy adults do not share the disease burden evenly with older people and those with preexisting conditions. As of May 13, 2020, death rates-reflecting the likelihood of dying from contracting the virus-of the 20 to 29 and 30 of 39 age groups were both $0.2 \%$, which starkly contrast death rates of $8 \%$ for those aged 70 to 79 years and $14.8 \%$ for those older than 80 years. ${ }^{11,13}$ While the Centers for Disease Control and Prevention highlights that people in the 20 to 44 age group are susceptible to contracting the virus and requiring hospitalization, ${ }^{13}$ most young people who contract the virus appear to be likely to survive. Whatever data one chooses to highlight, the people in their 20s and 30s whom I have encountered, both in my personal life and in witnessing the public sphere, nearly unanimously voice that their precautions are for the safety of others. One 32-year-old man, when asked why he isolates, stated, "I don't want to get the virus, but I'm much more worried about passing it on to vulnerable people.” Another said that if he could choose to get the virus without infecting others, he likely would. This evidence, although anecdotal and skewed towards my scope of experience, indicates that some people are motivated to accept a dramatic alteration of their lives for the safety of others. From observing people in my life and popular figures in the media, I believe many people are in this category.

Some have specific individuals they aim to protect by practicing virus etiquette, namely, vulnerable family members and close friends. These are people who, while not primarily concerned about their own health, are also not necessarily motivated by the idea of protecting the human population at large. Still, I find these family values to illuminate the potential for people who primarily think about their families to think in more global terms.

Heightened protection of family is explicable from an evolutionary perspective, both when thinking anthropologically about humanity's roots in small, competing primate societies ${ }^{14}$ and biologically through a consideration of gene propagation. ${ }^{15}$ Books have been written on these concepts and their 
relationships to altruism and human collaboration. ${ }^{14,15}$ Still, a point of emphasis is that humans, through an ability to imagine a shared experience and create society, have stepped aside from many of the behaviors that biology alone would predict. ${ }^{14,15}$ The society humans have created enables both collaboration with strangers and development of a particularly strong connection with family members and friends. For example, we can drive to grocery stores, stopping at imaginary barriers in the streets marked only by colored lights, hand paper to cashiers in exchange for food, and then return to the comfort of our families and friends with whom we most associate.

Society enables tolerance, and even appreciation, of strangers to enjoy time with family and friends. A key element of this arrangement is that there are many interweaving groups of social connections and an awareness that a stranger to one person is a close friend to another. In this view, people who choose to isolate explicitly to protect their families are aligned with how society naturally functions, by balancing participation in society at large with a particular concern for a smaller unit within that society. The COVID-19 pandemic demonstrates that people are willing to apply the social contract of everyday life to a significant life-changing event. In terms of AMR, these individuals may similarly be motivated to protect members of their cohort at the expense of some portion of their safety by agreeing to a social contract that incorporates antimicrobial stewardship.

In my estimation, many people are ready to think about global health. Certainly, some are not ready, but others already have this focus. Consider the 14000 people volunteering to participate in a vaccine trial that involves intentional infection with the virus. ${ }^{16}$ If large-scale thinking begins to seep into everyday conversation, it seems reasonable to imagine that humans will continue in the trend towards expanding the in-group. COVID-19 is forcing big picture conversations. We are confronted with the idea of global health through the disruption of our daily lives, and this may open the door to more discussions about human collaboration, including the partnership needed to confront AMR.

So far, I have discussed 3 considerations that motivate people's willingness to follow COVID-19 precaution recommendations: to protect themselves, to protect vulnerable family members or friends, and to protect the global community. A fourth, possibly confounding, reason is that many people simply follow the tracks laid for them. Some people do not realistically have a choice of whether to take on personal detriment to slow the spread of SARS$\mathrm{CoV}-2$ and are, by circumstance, left acting in line with recommendations for decreasing the burden (i.e., essential workers). Although people are not strictly mandated to avoid contact, at least not in the United States, many have lost jobs, others have transitioned to a work-from-home environment, and most social interaction sites have closed. Even for those who do feel a sense of agency 
around physical-distancing practices, each person's decision to wear a mask in public or postpone a social event may be tied to the fact that these decisions are the new norm.

I remember studying for medical school exams as the burden of COVID-19 was starting to increase in the United States, leading to uncertainty about whether or not the exams would be taken in person. Much of the country appeared to be uncertain about how seriously to treat the threat of COVID-19. At some point, around when the NBA cancelled its season, the country reached a critical threshold, with enough people paying serious attention to the problem that the appropriate decision became obvious. In the end, we took our remaining exams remotely. Once our country reached this threshold, physical distancing became the path of least resistance in many situations. Now, to be the only person in a grocery store without a mask is often uncomfortable, for example, making those who were previously uncertain about their use more likely to wear masks in grocery stores. This reality might pollute some of the optimism I have endorsed up to this point; it is possible that people promote altruistic ideals and cite admirable reasons for isolating, but when it comes down to actions, would be more self-centered if truly given the choice.

Redemption for my tentative optimism can be found, however, in the idea that personal and global concerns are not isolated entities. The new norm of physical distancing arose from a series of decisions made by concerned individuals who were likely considering their own lives, the safety of their family members and close friends, and the safety of strangers. Health care workers, politicians, business owners, artists, and educators are some of the individuals who have made decisions that have contributed to the new norm. Personally, I have been surprised and encouraged by the dramatic ways people have changed their lives in response to COVID-19. At base, no matter the reason for shifts in pandemic-oriented society, we have seen major changes in behavior.

\section{Future Implications:}

The world's response to COVID-19 highlights that humans, though far from perfectly, are able to rapidly communicate and adapt their behaviors. I wonder if the changes in behavior we have seen will contribute to changes in attitudes towards infectious diseases in general. However, the response to COVID-19 also highlights that humans may need an immediate existential threat to mobilize such a sweeping movement. AMR, by the accounts of infectious disease experts, ${ }^{3,17}$ will lead to another existential threat. Therefore, the questions become (1) will COVID-19 function as a wake-up call for the potential dangers of infectious diseases in the AMR arena and (2) will people support efforts to thwart these diseases even if this assumes increased individual risk in some situations? 
Future research assessing opinions related to AMR and antimicrobial stewardship can help illuminate answers to these questions. For now, I argue that the response to COVID-19 provides evidence that many people will be receptive to learning about and taking steps towards preventing future difficult-to-treat microbial infections. If research about public attitudes towards AMR supports this argument, then maybe it is time to strengthen and broaden antibiotic stewardship programs in an effort to protect the greatest number of patients, present and future. If, on the other hand, the idea of protecting future patients by limiting antibiotic use for current patients is not palatable, a case could be made for emphasizing other avenues of microbial management.

Either way, an effective approach will likely require a balancing of many strategies, including raising awareness of the problem, promoting antibiotic stewardship, and incentivizing drug companies to develop antimicrobials. ${ }^{7}$ Still, information about the values held by fellow citizens of the world can help guide the incorporation of these strategies. As we lumber through the COVID-19 crisis, I invite you to consider the behaviors and motivations of the people around you. Are people interested in protecting the human project, present, and future? Are you? 


\section{REFERENCES}

1. Rawson TM, Moore LSP, Zhu N, et al. Bacterial and fungal coinfection in individuals with coronavirus: A rapid review to support COVID-19 antimicrobial prescribing. Clin Infect Dis. Clin Infect Dis. Published online May 2, 2020. Accessed May 11, 2020. https://academic.oup.com/cid/ advance-article/doi/10.1093/cid/ciaa530/5828058

2. McKenna M. Covid-19 may worsen the antibiotic resistance crisis. WIRED. https://www.wired.com/story/covid-19-may-worsen-the-antibiotic-resistance-crisis/. Published April 23, 2020. Accessed April 23, 2020.

3. Ventola CL. The antibiotic resistance crisis: Part 1: causes and threats. $P E^{\circ} T$. 2015;40(4):277-283. https://www.ncbi.nlm.nih.gov/pubmed/25859123

4. O'Neill J. Antimicrobial resistance: Tackling a crisis for the health and wealth of nations. Published December. Published online 2014. Accessed May 11, 2020. https://amr-review.org/sites/ default/files/

AMR\%20Review\%20Paper\%20-\%20Tackling\%20a\%20crisis\%20for\%20the\%20health\%20and\%20wealth\%20of\%20nation

5. World Health Organization. Coronavirus disease (COVID-19) situation reports. Accessed May 11, 2020. https:/www.who.int/emergencies/diseases/novel-coronavirus-2019/situation-reports

6. World Health Organization. Antimicrobial resistance: From global agenda to national strategic plan, Thailand. Accessed May 11, 2020. http://www.who.int/bulletin/volumes/95/8/16-179648/ en/

7. McCarthy M. Superbugs: The Race to Stop an Epidemic. Penguin Random House; 2019.

8. Doron S, Davidson LE. Antimicrobial stewardship. Mayo Clin Proc. 2011;86(11):1113-1123. doi: $10.4065 / \mathrm{mcp} .2011 .0358$

9. McGowan JE Jr, Gerding DN. Does antibiotic restriction prevent resistance? New Horizons (Baltimore, Md). 1996;4(3):370-376. Accessed May 11, 2020. https://europepmc.org/article/med/ $\underline{8856755}$

10. Simon M. Over 1,000 health professionals sign a letter saying, don't shut down protests using coronavirus concerns as an excuse. CNN. https://www.cnn.com/2020/06/05/health/health-careopen-letter-protests-coronavirus-trnd/index.html. Published June 5, 2020. Accessed June 13, 2020.

11. Worldometer. Age, sex, existing conditions of COVID-19 cases and deaths.https://www.worldometers.info/coronavirus/coronavirus-age-sex-demographics/. Published May 13, 2020. Accessed June 13, 2020.

12. Lewis T. How to Evaluate Coronavirus Risks from the Black Lives Matter Protests. Scientific American. Accessed June 24, 2020. https://www.scientificamerican.com/article/how-to-evaluatecoronavirus-risks-from-black-lives-matter-protests/

13. Centers for Disease Control and Prevention. Severe Outcomes Among Patients with Coronavirus Disease 2019 (COVID-19) - United States, February 12-March 16, 2020. MMWR Morb Mortal Wkly Rep. 2020;69(12):343-346. doi:10.15585/mmwr.mm6912e2

14. Harari YN. Sapiens: A Brief History of Humankind. HarperCollins Publishers; 2015.

15. Dawkins R. The Selfish Gene. 40th ed. Oxford University Press; 2016.

16. Ramgopal K. Why have 14,000 people volunteered to be infected with coronavirus?https://www.nbcnews.com/health/health-news/why-have-14-000-peoplevolunteered-be-infected-coronavirus-n1203931. Published May 10, 2020. Accessed May 12, 2020. 17. Dadgostar P. Antimicrobial resistance: implications and costs. Infect Drug Resist. 2019;12:3903-3910. doi:10.2147/idr.s234610 